\title{
Quantitative risk stratification and individual comprehensive therapy for invasive bladder cancers in China
}

\author{
Hai Tao Niu $\cdot$ Shi Xiu Shao $\cdot$ Zong Liang Zhang • \\ Shuai Wu · Bo Cheng · De Quan Pang · Ya Jun E • \\ Sheng Guo Dong · Guang Sun · Ji Wu Chang
}

Published online: 21 October 2008

(C) Springer Science+Business Media, B.V. 2008

\section{Erratum to: Int Urol Nephrol DOI 10.1007/s11255-008-9470-4}

The given names of several authors were misrepresented in the original publication.

The online version of the original article can be found under doi:10.1007/s11255-008-9470-4.

H. T. Niu ( $₫)$ · S. X. Shao · S. G. Dong Department of Urology, The Affiliated Hospital of Medical College Qingdao University, 16 Jiangsu Road, Qingdao 266003, China

e-mail: Niuhaitao1976@yahoo.com.cn

\section{Z. L. Zhang - S. Wu}

Department of Urology, The Affiliated Municipal Hospital of Medical College Qingdao University, Qingdao 266003, China

\section{B. Cheng}

Department of Urology, The Central Hospital of Shengli

Oil Field, Dondying 257000, China

D. Q. Pang

Department of Oncology, North China Coal Medical College, Tangshan 063000, China

Y. J. E · G. Sun · J. W. Chang Department of Urology, Tianjin Institute of Urology, The Second Hospital of Tianjin Medical University, Tianjin 300211, China 